\title{
Analisis Percepatan Getaran Tanah Maksimum Akibat Gempabumi Di Wilayah Nusa Tenggara Dengan Metode Probablistic Seismic Hazard Analysis (PSHA)
}

\author{
Uzlifatul Azmiyati \\ Program Studi Teknik Lingkungan, Fakultas Teknik, Universitas Nahdlatul Ulama NTB \\ Jalan Pendidikan No. 6 Dasan Agung Baru, Kecamatan Selaparang, Kota Mataram, NTB \\ E-mail: u.azmiyati@gmail.com
}

\begin{abstract}
Abstrak. Wilayah kepulauan Nusa Tenggara berada pada zona pertemuan lempeng tektonik dan memiliki sesar-sesar aktif. Kondisi ini menyebabkan wilayah ini sering dilanda bencana gempabumi. Oleh karena itu penelitian mengenai percepatan maksimum tanah (peak ground acceleratio (PGA) yang menggambarkan tingkat bahaya akibat gempa menjadi penting sebagai langkah mitigasi awal. Metode yang digunakan dalam penelitian ini adalah metode probabilistic seismic hazard analysis (PSHA) dengan bantuan perangkat lunak USGS PSHA 2007. Metode PSHA memperhitungkan dan menggabungkan ketidakpastian dari mekanisme kejadian gempa, lokasi dan kejadian frekuensi gempa untuk mendapatkan gambaran tingkat bahaya suatu lokasi. Tingkat bahaya tersebut ditunjukkan dalam bentuk nilai PGA. Penelitian ini menggunakan data dari katalog gempa NEIC-USGS dan BMKG untuk daerah wilayah Kepulauan NusaTenggara antara $4^{0}-12^{\circ}$ LS dan $110^{\circ}-125^{\circ}$ BT dari tahun 1973 sampai tahun 2011. Analisis yang telah dilakukan menghasilkan variasi nilai PGA antara 0g-0,50g. Dari peta PGA diketahui bahwa daerah Pulau Sumbawa, Sumba, Timor, Flores dan Kupang memiliki tingkat bahaya gempabumi tinggi dengan nilai PGA antara 0,25g - 0,50g. Daerah Pulau Bali dan Lombok bagian Selatan memiliki tingkat bahaya gempa rendah dengan nilai PGA antara $0,1 \mathrm{~g}-0,25 \mathrm{~g}$.
\end{abstract}

Kata kunci : Percepatan maksimum tanah, PSHA, Kepulauan Nusa Tenggara

Abstract. The area of Nusa Tenggara is located on the convergent plate boundary having active faults. This condition often causes of earthquakes. Therefore, the research of peak ground acceleration (PGA) describing the potential danger of earthquake becomes important as the first step of mitigation. The method applied in this research is probabilistic seismic hazard analysis method (PSHA) using USGS PSHA 2007 software. PSHA method takes account for unpredictable earthquake mechanism, location, and frequent accident of earthquake to obtain the detailed description of the potential danger at a certain location. The level of the danger is indicated by PGA values. The data used is taken from NEIC-USGS and BMKG for the area of $4^{0}-12^{0}$ south latitude and $110^{\circ}-125^{\circ}$ east longitude in 1973 until 2011. The result of analysis show the variation of PGA values are between $0 \mathrm{~g}-0,50 \mathrm{~g}$. PGA map shows that the area of Sumbawa, Sumba, Timor, Flores, and Kupang have high earthquake risk with PGA values between $0,25 \mathrm{~g}-0,50 \mathrm{~g}$. The area of Bali and Southern Lombok have low risk of earthquake with PGA values between $0,1 \mathrm{~g}-0,25 \mathrm{~g}$.

Keyword: Peak ground acceleration, PSHA, Nusa Tenggara Island 


\section{PENDAHULUAN}

Kepulauan Indonesia merupakan daerah yang relatif rawan terhadap bencana gempabumi tektonik. Hal ini disebabkan karena kepulauan Indonesia terletak pada kerangka tektonik yang didominasi oleh interaksi dari empat lempeng utama yang berbeda jenis (kerak samudera dan kerak benua) yaitu lempeng Eurasia, lempeng Hindia-Australia, lempeng Pasifik dan lempeng Philipina. Akibat pertemuan antara lempeng tersebut maka terbentuk daerah penunjaman atau subduksi (subduction zone), yang mengakibatkan kepulauan Indonesia memiliki aktivitas seismik yang tinggi dan mempengaruhi tingkat seismisitas di antara wilayah-wilayah di Indonesia (Rochim, 2008).

Tingginya tingkat bahaya gempabumi pada wilayah-wilayah di Indoneisa dapat dilihat pada beberapa gempabumi besar yang terjadi dalam 20 tahun terakhir yaitu gempabumi Flores (1992), gempabumi Biak (1996), gempabumi Nabire, Alor dan Aceh yang berkekuatan sangat besar (2004), gempabumi Mentawai dan Padang (2005), gempabumi Gunung Sitoli (2005), gempabumi Yogyakarta (2006) dan gempabumi Papua (2009). Gempabumi telah dikenal sebagai fenomena alam yang menimbulkan efek bencana yang paling besar, baik secara moril maupun materil. Suatu kejadian gempabumi dapat mengakibatkan kerusakan total pada bangunan-bangunan penting dan sarana infrastruktur serta menimbulkan korban jiwa yang tidak sedikit. Gempabumi merupakan peristiwa alam yang tidak dapat diprediksi dan dihentikan kejadiannya karena terjadi secara tiba-tiba. Kita hanya dapat mengurangi dampak yang ditimbulkannya.

Untuk meminimalisasi bahaya yang diakibatkan oleh gempabumi diperlukan suatu langkah mitigasi. Salah satu upaya mitigasi yang dapat dilakukan adalah dengan melakukan analisis seismik hazard untuk mendapatkan peta hazard atau peta percepatan getaran tanah maksimum (Peak ground acceleration /PGA) yang menggambarkan efek gempabumi pada suatu lokasi.

Untuk melakukan analisis seismik hazard dapat menggunakan dua metode yaitu metode PSHA (Probabilistic Seismic Hazard Analysis) (Cornell, 1968) dan metode DSHA (Deterministic Seismic Hazard Analysis) (McLuhan, 1962). Dalam metode DSHA skenario kejadian gempabumi telah ditentukan. Skenario gempa bumi ini berisi tentang kejadian gempabumi dengan magnitudo tertentu yang akan terjadi pada lokasi tertentu. Sedangkan metode PSHA berdasarkan suatu fungsi distribusi probabilitas yang memperhitungkan pengaruh faktor-faktor ketidakpastian dari ukuran, lokasi dan waktu kejadian gempabumi. Dengan menggunakan metode PSHA dapat diketahui tingkat bahaya gempabumi di suatu lokasi yang ditinjau. Bahaya yang terjadi kemudian didefinisikan dalam bentuk nilai PGA. Metode PSHA lebih sering digunakan karena memberikan kerangka kerja yang terarah sehingga faktor-faktor ketidakpastian dapat diidentifikasi, diperkirakan, dan kemudian digabungkan untuk mendapatkan gambaran menyeluruh mengenai tingkat bahaya gempabumi.

Beberapa penelitian yang pernah dilakukan di berbagai daerah di Indonesia dengan menggunakan metode PSHA yaitu di wilayah Sumatera (Sengara dkk, 2008), menghasilkan peta percepatan getaran tanah maksimum dengan nilai berkisar antara $0,10 \mathrm{~g}-0,70 \mathrm{~g}$. Wilayah Jawa-Sumba dan 
Jurnal Ilmu Sosial dan Pendidikan

http://ejournal.mandalanursa.org/index.php/JISIP/index

Terakreditasi Peringkat 5 (No. SK: 85/M/KPT/2020)
Vol. 5. No. 1 Januari 2021

p-ISSN: 2598-9944 e- ISSN: 2656-6753
Kalimantan (Aldiamar, 2009), menghasilkan peta percepatan getaran tanah maksimum dengan kisaran nilai percepatan $0,005 \mathrm{~g} \quad-\quad 0,9 \mathrm{~g}$. Untuk wilayah kota Bitung Sulawesi Utara (Pasau, 2011) menghasilkan peta percepatan getaran tanah maksimum sekitar $0,7 \mathrm{~g}$. Metode PSHA juga digunakan untuk mengembangkan peta zonasi gempa Indonesia.

Dalam penelitian ini digunakan metode PSHA dengan lokasi kajian di Kepulauan Nusa Tenggara. Lokasi kajian wilayah Kepulauan Nusa Tenggara dilakukan karena penelitian yang difokuskan pada wilayah ini dengan menggunakan metode PSHA belum banyak dilakukan oleh para ahli. Wilayah Kepulauan Nusa Tenggara berdasarkan catatan dan kondisi tektoniknya memiliki aktivitas gempabumi yang cukup tinggi dan mengalami pertumbuhan penduduk yang sangat pesat, sehingga diperlukan langkah mitigasi awal dengan membuat peta percepatan getaran tanah maksimum atau peta hazard untuk meminimalisasi dampak bencana gempabumi yang terjadi. Tujuan dari penelitian ini adalah untuk (1) Mengetahui variasi nilai percepatan getaran tanah maksimum (PGA) di wilayah Kepulauan Nusa Tenggara. (2) Membuat peta percepatan getaran tanah maksimum (PGA) atau peta hazard dengan metode PSHA untuk mengetahui daerah-daerah yang memiliki tingkat bahaya bencana gempabumi tinggi di wilayah Kepulauan Nusa Tenggara.

\section{TINJAUAN PUSTAKA}

\section{Kondisi Tektonik Wilayah Kepulauan Nusa Tenggara}

Secara tektonik, wilayah Kepulauan Nusa Tenggara bagian selatan merupakan bagian dari kerangka sistem tektonik Indonesia. Daerah ini termasuk dalam jalur gempabumi Mediteranian dan berada pada zona pertemuan lempeng tektonik. Pertemuan kedua lempeng ini bersifat konvergen di mana keduanya bertumbukan (zona subduksi) dan salah satunya yaitu lempeng Indo-Australia menyusup ke bawah lempeng Eurasia dimana Kepulauan Nusa Tenggara berada di atasnya. Zona-zona subduksi tersebut merupakan zona-zona sumber gempabumi yang memberikan kontribusi yang signifikan terhadap kejadian gempabumi yang telah lalu dan yang akan datang. Gempabumi yang terjadi pada zona subduksi umumnya dipisahkan atas dua kelompok, yaitu gempabumi Megathrust yang merupakan gempabumi akibat penyusupan dangkal dan gempabumi Benioff yang merupakan gempabumi akibat penyusupan dalam. Zona Megathrust adalah bagian dangkal dari zona subduksi yang mempunyai sudut yang landai, sedangkan zona Benioff adalah bagian dari zona subduksi yang mempunyai sudut yang curam.

Selain kerawanan seismik akibat aktivitas benturan lempeng (subduksi) di Samudera Hindia selatan Kepulauan Nusa Tenggara, kawasan Kepulauan Nusa Tenggara juga rawan akibat adanya sebuah struktur tektonik patahan naik busur belakang kepulauan yang dikenal sebagai back arc thrust. Struktur ini terbentuk akibat tunjaman balik lempeng Eurasia terhadap lempeng Samudera Indo-Australia (Daryono, 2006, dalam Nugroho, 2008).

Fenomena tumbukan busur benua (arc continent collision) diduga sebagai pengendali mekanisme deformasi patahan naik ini. Back arc thrust membujur di laut utara Bali hingga laut Flores sejajar dengan busur Kepulauan Bali dan Nusa Tenggara. Fenomena patahan naik busur belakang kepulauan ini cukup aktif dalam 
membangkitkan gempa-gempa tektonik di kawasan tersebut (Daryono, 2004, dalam Nugroho, 2008).

Aktivitas gempabumi yang sering terjadi akibat tatanan tektonik wilayah Kepulauan Nusa Tenggara juga akan menjadi pemicu (trigger) aktifnya sesarsesar lokal yang menjadikan semakin rumit dan kompleksnya seismisitas di wilayah Kepulauan Nusa Tenggara. Sesar aktif (fault) yang terdapat di lempeng tektonik dalam perkembangannya juga mengalami pergerakan dan akan memberikan kontribusi terhadap kejadian gempabumi. Mekanisme pergerakan sesar ini dapat berupa geser (strike-slip), naik (reverse), dan turun (normal) (Nugroho, 2008).

\section{Probabilistic Seismic Hazard Analysis (PSHA)}

PSHA merupakan metode yang dapat digunakan untuk menganalisis seismik hazard. Metode ini digunakan dalam analisis bahaya kegempaan berdasarkan definisi fungsi distribusi probabilitas yang memperhitungkan dan menggabungkan ketidakpastian dari mekanisme kejadian gempabumi, lokasi, dan frekuensi kejadian gempa untuk mendapatkan gambaran yang menyeluruh mengenai tingkat bahaya suatu lokasi yang ditinjau. Bahaya yang terjadi kemudian didefinisikan dalam bentuk nilai PGA pada lokasi tersebut.

Penentuan besarnya nilai PGA dengan metode PSHA melibatkan beberapa ketidakpastian yang dikelompokkan menjadi dua yaitu; (1) Ketidakpastian aleatory yang muncul karena proses/kejadian alamiah yang variasinya tidak dapat diprediksi. Contoh dari ketidakpastian aleatory adalah lokasi gempabumi, magnitudo dan karakteristiknya serta proses pecahnya fault. (2) Ketidakpastian epistemic yang muncul karena masih kurangnya pengetahuan tentang mekanika proses gempabumi dan masih kurangnya data. Beberapa ketidakpastian epistemic penting yang berhubungan dengan parameter kegempaan, yaitu dalam penentuan lokasi dan batas/luasan sumber gempabumi, distribusi gempabumi dan magnitudo maksimum, seismisitas (activity rate) dan variasi karakteristik ground motion dalam rumus atenuasi (McGuire, 2004 dalam Irsyam dkk, 2010).

Percepatan Getaran Tanah Maksimum (PGA)

Percepatan adalah parameter yang menyatakan perubahan kecepatan tanah mulai dari keadaan diam sampai pada kecepatan tertentu. Ketika terjadi sebuah gempa dengan kekuatan (magnitudo) tertentu, maka gempa tersebut akan menggetarkan tanah atau batuan yang dilewatinya sehingga batuan tersebut mengalami percepatan. Percepatan yang terjadi akibat gempa inilah yang disebut dengan percepatan getaran tanah. Percepatan getaran tanah merupakan gangguan yang perlu dikaji untuk setiap kejadian gempabumi, kemudian dipilih nilai PGA untuk mengetahui efek paling parah yang pernah dialami suatu lokasi.

PGA adalah nilai percepatan getaran tanah terbesar yang pernah terjadi di suatu tempat yang diakibatkan oleh gempabumi. Dalam PSHA percepatan maksimum tanah dihasilkan dengan menghubungkan parameter sumber gempa dengan parameter pergerakan tanah di lokasi studi dengan menggunakan fungsi atenuasi gelombang sebagai fungsi magnitudo dan jarak.

Percepatan getaran tanah maksimum yang dihasilkan berbeda-beda pada setiap daerah sesuai dengan kondisi geologinya. Nilai PGA merupakan salah satu faktor yang menjadi sumber kerusakan ketika terjadi gempabumi. Data PGA pada suatu lokasi menjadi penting 
Jurnal Ilmu Sosial dan Pendidikan

http://ejournal.mandalanursa.org/index.php/JISIP/index

Terakreditasi Peringkat 5 (No. SK: 85/M/KPT/2020)

untuk menggambarkan tingkat bahaya gempabumi di suatu lokasi tertentu. Semakin besar nilai PGA yang pernah terjadi disuatu tempat, maka semakin besar bahaya gempabumi yang mungkin terjadi.

\section{METODE PENELITIAN}

Jenis penelitian ini adalah penelitian kuantitatif untuk mendapatkan nilai PGA dengan menggunakan metode PSHA yang menggunakan data sekunder berupa data dan parameter gempa dari katalog gempa NEICUSGS dan BMKG sedangkan data dan parameter sesar serta data dan parameter subduksi untuk wilayah Kepulauan Nusa Tenggara diperoleh dari Tim Teknis Revisi Peta Gempa Indonesia 2010. Data yang digunakan dalam penelitian ini adalah (1) Data dan parameter kejadian gempa di wilayah Kepulauan Nusa Tenggara, (2) Data dan parameter sesar dan subduksi di wilayah Kepulauan Nusa Tenggara. Alat yang dipergunakan dalam analisis data adalah seperangkat komputer dengan software ZMAP, USGS-PSHA 2007, Surfer 9, dan Microsoft Excel 2007.

Selanjutnya dilakukan Identifikasi terhadap sumber gempabumi dan mekanismenya meliputi lokasi, dimensi, jenis mekanisme sumber gempabumi dan tingkat aktifitasnya berdasarkan data gempabumi dari katalog gempabumi USGS-NEIC dan BMKG. Batasan pemodelan zona sumber gempabumi yang digunakan adalah sebagai berikut: Kedalaman sumber gempabumi dibatasi hingga $300 \mathrm{~km}$, fungsi atenuasi yang digunakan untuk tiap-tiap model sumber gempabumi adalah fungsi atenuasi yang dianggap sesuai dengan karakteristik kegempaan dan model sumber gempabumi wilayah Indonesia. Terdapat tidag model sumber gempabumi yang digunakan yaitu: gempabumi background, gempabumi sesar (fault) dan gempabumi subduksi.
Vol. 5. No. 1 Januari 2021

p-ISSN: 2598-9944 e- ISSN: 2656-6753 $\begin{array}{lcr}\text { Analisis } & \begin{array}{c}\text { seismik hazard } \\ \text { bantuan }\end{array} & \begin{array}{r}\text { dilakukan } \\ \text { software }\end{array} \\ \text { dengan } & \text { 2007. Software USGS PSHA } \\ \text { USGS PSHA } & \text { 2007. } \\ 2007 \text { merupakan softwarer yang }\end{array}$ dikembangkan oleh USGS di Golden Colorado untuk melakukan analisis seismik hazard yang bersifat open source. Software yang dikembangkan dengan bahasa Fotran 95 ini memiliki potensi sebagai alat bantu analisis seismik hazard (Bella, 2009). Adapun sumber gempabumi yang digunakan adalah sumber gempabumi background, sumber gempabumi sesar (fault) dan sumber gempabumi subduksi. Sumber gempabumi background input datanya dibuat dalam suatu sub-program agrid. Parameter yang diinputkan dalam sumber gempabumi background adalah lokasi gempabumi (longitude dan latitude), magnitudo, kedalaman, tahun kejadian, magnitude of completeness, nilai $b$, magnitudo minimum dan magnitudo maksimum. Kemudian analisa hazard untuk sumber gempabumi background dilakukan pada suatu sub-program yang bernama hazgrid. Untuk sumber gempabumi sesar (fault) input data dibuat dalam suatu sub-program yang disebut filtrate. Parameter yang diinputkan dalam sumber gempabumi sesar (fault) adalah lokasi gempabumi, magnitudo, kedalaman, tahun kejadian, lokasi sesar, mekanisme pergerakan sesar, slip-rate, dip, nilai $b$, magnitudo maksimum sesar, panjang dan lebar sesar. Analisa hazard sumber gempabumi sesar dilakukan pada suatu subprogram yang bernama hazFXnga. Untuk sumber gempabumi subduksi input dan analisa hazard-nya disatukan dalam suatu sub-program yang bernama hazsub. Parameter yang diinputkan dalam sumber gempabumi subduksi adalah lokasi gempabumi, magnitudo, kedalaman, tahun kejadian, lokasi 
subduksi, nilai $a-b$, magnitudo minimum dan magnitudo maksimum. Hasil analisis hazard dari ketiga sumber gempabumi tersebut berupa nilai PGA yang kemudian digabungkan dalam suatu sub-program yang disebut hazall untuk mendapatkan nilai PGA untuk sumber gempabumi gabungan.

\section{HASIL DAN PEMBAHASAN}

Peta PGA Akibat Sumber Gempabumi Background

Peta PGA yang dihasilkan akibat sumber gempabumi background untuk wilayah Kepulauan Nusa Tenggara adalah seperti yang terlihat pada Gambar 1.1.

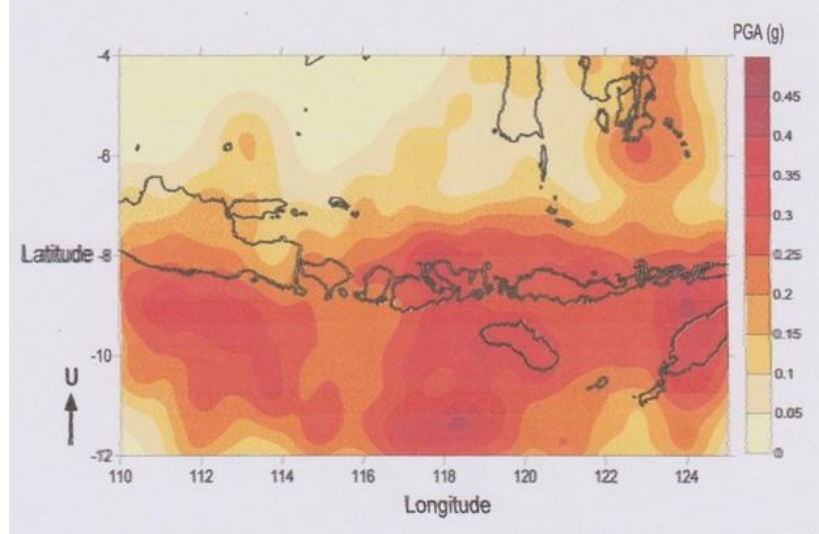

Gambar 1.1. Peta PGA akibat sumber gempabumi background

Dari peta PGA Gambar 1.1 di atas dapat dilihat distribusi spasial nilai PGA di wilayah Kepulauan Nusa Tenggara akibat sumber gempabumi background. Daerah-daerah di wilayah ini ada yang memiliki nilai PGA rendah, sedang maupun tinggi. Nilai PGA yang dihasilkan akibat sumber gempabumi background berkisar antara $0 \mathrm{~g}$ $0,5 \mathrm{~g}, \mathrm{~g}$ merupakan percepatan gravitasi sebesar $9,8 \mathrm{~m} / \mathrm{s}^{2}$. Untuk nilai PGA antara $\quad 0 \mathrm{~g}-0,1 \mathrm{~g}$ berada di wilayah Baratlaut dan Utara dari Kepulauan Nusa Tenggara. PGA dengan nilai antara 0,1g-0,25g dominan di sebelah Selatan, Utara, dan Barat Pulau Bali, serta di bagian Utara Pulau Alor. Untuk PGA dengan kisaran nilai antara $0,25 \mathrm{~g}-0,5 \mathrm{~g}$ dominan di sebelah Baratdaya Pulau Bali, bagian Utara dan Selatan Pulau Sumbawa, Pulau Sumba, Pulau Timor, Pulau Flores.

Berdasarkan peta PGA tersebut terlihat bahwa gempa-gempa yang terjadi di wilayah Kepulauan Nusa Tenggara banyak diakibatkan oleh sumber gempa background. Daerah Pulau Bali memiliki nilai PGA dengan kisaran $0,2 \mathrm{~g}-0,25 \mathrm{~g}$, nilai yang sama di Pulau Lombok bagian Selatan. Pulau Lombok bagian Utara memiliki nilai PGA yang lebih besar dari Pulau Lombok bagian Selatan yaitu berkisar antara $0,25 \mathrm{~g}-0,3 \mathrm{~g}$. Hal ini disebabkan karena adanya gunung api Rinjani di daerah tersebut yang mempengaruhi nilai PGA. Daerah Sumbawa, Timor, Flores, Sumba, dan Kupang memiliki nilai PGA yang tinggi yaitu dengan kisaran nilai antara $0,25 \mathrm{~g}$ $0,45 \mathrm{~g}$. Nilai PGA yang tinggi di daerah ini disebabkan karena di daerah ini banyak terdapat gunung berapi dan letaknya yang berdekatan dengan lokasi sesar dan lokasi zona subduksi pertemuan Lempeng Indo-Australia dengan Lempeng Eurasia. Adanya gunung berapi, sesar dan zona subduksi maka akan sangat mempengaruhi nilai PGA yang dihasilkan.

Peta PGA Akibat Sumber Gempabumi Sesar (Fault)

Sesar yang telah teridentifikasi dengan baik dan memberikan nilai hazard yang cukup signifikan di wilayah Kepulauan Nusa Tenggara adalah sesar Flores back-arc dan sesar Timor backarc. Kedua sesar ini terletak di bagian Utara wilayah Kepulauan Nusa Tenggara. Adapun peta (PGA) yang dihasilkan akibat sumber gempabumi sesar 
(fault) tersebut adalah seperti yang terlihat pada Gambar 1.2.

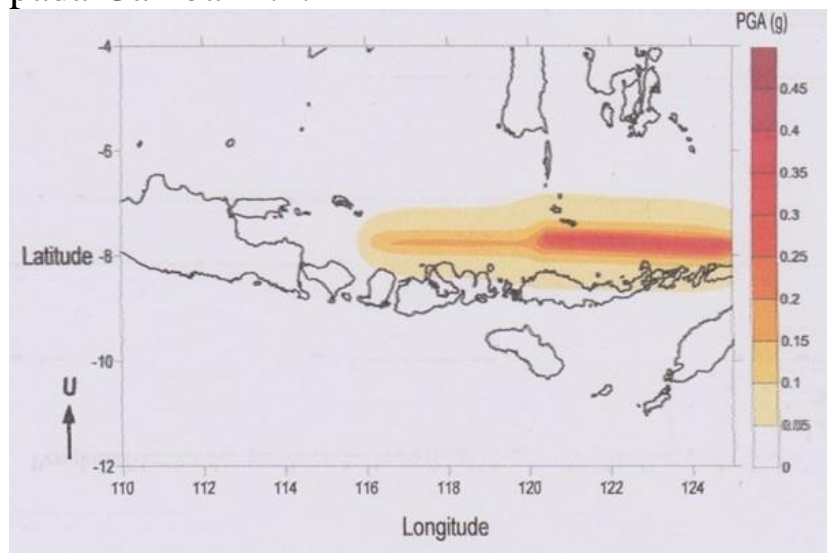

Gambar 1.2. Peta PGA akibat sumber gempabumi sesar (fault)

Dari peta PGA Gambar 4.3 dapat dilihat distribusi spasial nilai percepatan maksimum tanah (PGA) pada wilayah Kepulauan Nusa Tenggara akibat sumber gempabumi sesar (fault). Daerah-daerah di wilayah ini ada yang memiliki nilai PGA rendah, sedang maupun tinggi. Variasi nilai PGA akibat sumber gempa sesar (fault) yang dihasilkan berkisar antara $0 \mathrm{~g}-0,5 \mathrm{~g}, \quad \mathrm{~g}$ merupakan percepatan gravitasi sebesar 9,8 $\mathrm{m} / \mathrm{s}^{2}$. Nilai PGA $0 \mathrm{~g}-0,1 \mathrm{~g}$ akibat sumber gempa sesar mendominasi di wilayah penelitian ini. Untuk nilai PGA 0,1g-0,5g berada di wilayah Utara Pulau Lombok, Pulau Sumbawa dan di Kepulauan Flores, nilai PGA tersebut dominan di sekitar sesar Flores backarc dan sesar Timor back-arc yang menjadi salah satu sumber gempa di wilayah ini.

Berdasarkan peta percepatan maksimum tanah (PGA) akibat gempa sesar (fault) yang telah dihasilkan, diketahui bahwa nilai PGA yang tinggi terkonsentrasi di lokasi sesar. Nilai PGA $0,1 \mathrm{~g}-0,2 \mathrm{~g}$ terdapat $\mathrm{di}$ sepanjang lokasi sesar Flores back-arc dan nilai PGA 0,2g-0,5g terdapat di sepanjang lokasi sesar Timor back-arc. Nilai PGA lebih tinggi di lokasi sesar Timor back-arc disebabkan oleh nilai slipe-rate sesar Timor back-arc yang lebih besar daripada sesar Flores back-arc yaitu adalah $30 \mathrm{~mm} / \mathrm{th}$. Nilai slip-rate yang lebih besar menyebabkan pergerakan sesar ini lebih cepat sehingga lebih sering menyebabkan terjadinya gempabumi. Pergerakan sesar yang lebih cepat berarti bahwa gaya yang ditimbulkan juga besar sehingga kejadian gempabumi memiliki kekuatan besar yang menyebabkan nilai PGA tinggi. Sesuai dengan peta PGA Gambar 1.2 maka dapat ditunjukkan bahwa untuk daerah Pulau Bali, Pulau Lombok, Pulau Sumba dan Kupang tidak dipengaruhi oleh gempa akibat sesar. Pengaruh akibat gempa sesar juga tidak signifikan untuk daerah Sumbawa, Flores dan Timor.

\section{Peta PGA Akibat Sumber Gempabumi Subduksi (Megathrust)}

Sumber gempabumi subduksi yang digunakan dalam analisis ini adalah zona subduksi yang telah teridentifikasi dengan baik. Sumber-sumber gempa subduksi yang digunakan di wilayah ini adalah subduksi megathrust Sumba dan subduksi megathrust Timor. Adapun peta PGA yang dihasilkan akibat sumber gempabumi subduksi (megathrust) tersebut adalah seperti yang terlihat pada Gambar 1.3.

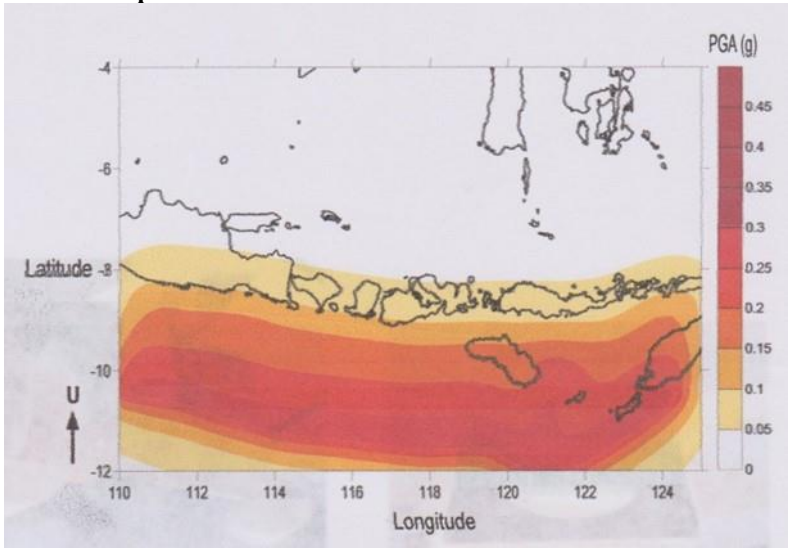

Gambar 1.3. Peta PGA akibat sumber gempabumi subduksi (megathrust)

Dari peta PGA Gambar 4.4 dapat dilihat variasi nilai percepatan 
Jurnal Ilmu Sosial dan Pendidikan

http://ejournal.mandalanursa.org/index.php/JISIP/index

Terakreditasi Peringkat 5 (No. SK: 85/M/KPT/2020)
Vol. 5. No. 1 Januari 2021

p-ISSN: 2598-9944 e- ISSN: 2656-6753 maksimum tanah (PGA) di wilayah Kepulauan Nusa Tenggara akibat sumber gempabumi subduksi (megathrust). Daerahdaerah di wilayah ini ada yang memiliki nilai PGA rendah, sedang maupun tinggi. Berdasarkan hasil pengolahan data dari katalog NEIC-USGS dan BMKG sejak 2 Januari 1973 sampai 24 Juli 2011, terlihat variasi nilai PGA akibat sumber gempa subduksi (megathrust) berkisar antara $0 \mathrm{~g}-0,5 \mathrm{~g}, \mathrm{~g}$ merupakan percepatan gravitasi sebesar $9,8 \mathrm{~m} / \mathrm{s}^{2}$. Nilai PGA $0 \mathrm{~g}$ akibat sumber gempa subduksi (megathrust) mendominasi di bagian Utara wilayah penelitian ini karena letaknya yang jauh dari zona subduksi. Daerah dengan nilai PGA $0 \mathrm{~g}$ berarti bahwa daerah tersebut memiliki tingkat bahaya gempabumi rendah, hal ini disebabkan karena gelombang gempa yang menjalar mengalami banyak pelemahan dan kemungkinan daerah tersebut terdiri dari batuan yang heterogen. Daerah Bali, Lombok, Sumbawa, Flores dan Alor memiliki nilai PGA sebesar 0,05g-0,1g. Untuk nilai PGA 0,1g-0,5g dominan berada di wilayah Sumba, Kupang, barat daya, selatan dan tenggara Kepulauan Nusa Tenggara, yaitu di sepanjang lokasi zona subduksi pertemuan Lempeng Indo-Australia dengan Lempeng Eurasia.

Nilai PGA tinggi mendominasi di lokasi zona subduksi pertemuan Lempeng Indo-Australia dengan Lempeng Eurasia dan di Pulau Sumba dan Kupang yang jaraknya sangat dekat dengan zona subduksi tersebut. Sumber gempa subduksi sangat mempengaruhi nilai PGA di Pulau Sumba dan Kupang. Untuk daerah Bali, Lombok, Sumbawa, Timor dan Flores sumber gempa subduksi tidak memberikan pengaruh yang besar karena nilai PGA untuk daerah tersebut rendah, yaitu antara $0,05 \mathrm{~g}-0,1 \mathrm{~g}$.

\section{KESIMPULAN}

Berdasarkan hasil pengolahan data gempabumi di wilayah Kepulauan Nusa Tenggara untuk mendapatkan nilai PGA dengan metode PSHA diperoleh simpulan sebagai berikut :

1. Nilai PGA yang dihasilkan memiliki variasi nilai antara $0 \mathrm{~g}-0,5 \mathrm{~g}$ ( $\mathrm{g}$ sama dengan $9,8 \mathrm{~m} / \mathrm{s}^{2}$ ).

2. Daerah yang memiliki tingkat bahaya gempabumi tinggi adalah Sumbawa, Sumba, Timor, Flores, Kupang dan Lombok bagian Utara. Sedangkan daerah Bali dan Lombok bagian Selatan memiliki tingkat bahaya gempabumi rendah.

\section{DAFTAR PUSTAKA}

Afnimar, 2009, Seismologi, Penerbit ITB, Bandung.

Aldiamar, F., 2009, Analisis Resiko Gempa Di Batuan Dasar. Jurnal JalanJembatan, Vol. 26, No. 3 Desember 2009, pp. 213-229.

Anbazhagan, P., Vinod, J. S., dan Sitharam, T. G., 2008, Probabilistic Seismic Hazard Analysis For Bangalore, Nat Hazard 48:145-166.

Bella, R. A., 2009, Pembuatan Program Interface Untuk Software USGS PSHA 2007 Dengan Studi Kasus Pembuatan Peta Spectra Hazard Di Wilayah Nusa Tenggara Timur. (http://digilib.itb.ac.id).

Field, E. H., Probabilistic Seismic Hazard Analysis (PSHA) A Primer.

(http://www.opensha.org/sites/opensh a.org/files/PSHA_Primer_v2_0.pdf).

Irsyam, M., Sengara, I.W., Aldiamar, F., Widiyantoro, S., Triyoso, W., dan Natawidjaja, D., 2010. Ringkasan Hasil Studi Tim Revisi Peta Gempa Indonesia 2010. Bandung.

Nugroho, H. A., 2008, Analisis Probabilitas 
Jurnal Ilmu Sosial dan Pendidikan

http://ejournal.mandalanursa.org/index.php/JISIP/index

Terakreditasi Peringkat 5 (No. SK: 85/M/KPT/2020)
Vol. 5. No. 1 Januari 2021

p-ISSN: 2598-9944 e- ISSN: 2656-6753
Gempabumi Daerah Bali Dengan
Distribusi

(http://hapsoroagung.files.wordpress.

com/2009/07/poisson.pdf). Stasiun

Geofisika Sanglah Denpasar, Bali.

Pasau, G., 2011, Respon Spektra

Gempabumi Di Batuan Dasar Kota

Bitung Sulawesi Utara Pada

Periode Ulang 2500

Tahun. Jurnal Sains, Vol. 11,

No. 1, April 2011.

Razali, 2008, Rekonturing Zona Percepatan

Gempa Di Permukaan Tanah

Provinsi Sumatera Utara dengan

Program Aplikasi Shake2000, Tesis,

Universitas Sumatera Utara.

Rochim, A., 2008, Analisa Probabilistik Hazard Gempa 3 Dimensi Dan Karakteristik Getaran Gempa Kota Semarang Untuk Respon Spektra Desain (http://digilib.itb.ac.id), Tesis, Institut Teknologi Bandung.

Sabtaji, A., Yogi, R. W., dan Isnaeni, Z., 2009, Estimasi Perhitungan Percepatan Tanah Gempabumi Utama Nabire dan Jogyakarta Menggunakan Data Accelerograph Gempabumi Susulan, Puslitbang BMKG, Jakarta.

Santoso, E., Widiyantoro, S., Sukanta, I. N., 2011, Studi Hazard Seismik Dan Hubungannya Dengan Intensitas Seismik Di Pulau Sumatera Dan Sekitarnya. Jurnal Meteorologi dan Geofisika, Vol. 12, No. 2, September 2011, pp. 129-136.

Sengara, I.W., Sumiartha, P., Natawidjaja, D., Triyoso, W., dan Hendarto, 2008, Probabilistic Seismic Hazard Mapping For Sumatra Island. Internasional Confrence on Earthquake Engineering and Disaster Mitigation, Jakarta, 14-15 April 2008.

Stein, S. dan Wysession, M., 2003, An Introduction To Seismology, Earthquakes, and Earth Structure,
Blackwell Publishing, United Kingdom.

Sunardi, B., 2009, Laporan Mitigasi Bencana, Puslitbang BMKG, Jakarta.

Suryani, T. A., 2007, Analisis Komparatif Nilai Parameter Seismotektonik Dari Hubungan Magnitudo-Kumulatif Dan Nonkumulatif Untuk Jawa Timur Menggunakan Metode Kuadrat Terkecil Dan Metode Maksimum Likelihood Dari Data BMG Dan USGS Tahun 1973-2003, Skripsi, Universitas Negeri Semarang.

Tim Penyusun Bidang Mitigasi Gempabumi dan Tsunami, 2009, Katalog Gempabumi Perwilayah, Badan Meteorologi Klimatologi dan Geofisika, Jakarta. 